\title{
GRANISETRON AND ONDANSETRON ON POST OPERATIVE NAUSEA AND VOMITING IN LAPAROSCOPIC CHOLECYSTECTOMY UNDER GENERAL ANESTHESIA AT BIR HOSPITAL KATHMANDU, NEPAL
}

\author{
Bhattarai $R^{1^{*}}$, Vaidya $P R^{2}$, Chand $M B^{3}$
}

\section{Affiliation}

1. Lecturer, Department of Anesthesiology, Karnali Academy of Health Sciences, Jumla, Karnali

2. Associate Professor, Department of Anesthesiology and Intensive care, Bir Hospital, NAMS

3. Professor, Department of Anesthesiology and Intensive care, Bir Hospital, NAMS

\section{ARTICLE INFO}

\section{Article History}

Received : 10 March, 2017

Accepted : 15 August, 2017

Published : 30 August, 2017

(C) Authors retain copyright and grant the journal right of first publication with the work simultaneously licensed under Creative Commons Attribution License CC - BY 4.0 that allows others to share the work with an acknowledgment of the work's authorship and initial publication in this journal.

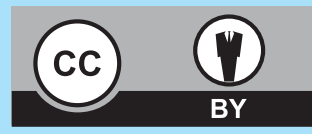

ORA 26

* Corresponding Author

Dr Ramesh Bhattarai

Lecturer, Department of Anesthesiology

Karnali Academy of Health Sciences Jumla, Karnali

Email: ramesh327@gmail.com

\section{Citation}

Bhattarai R, Vaidya PR , Chand M B. Granisetron and Ondansetron on Post Operative Nausea and Vomiting in Laparoscopic Cholecystectomy Under General Anesthesia at Bir Hospital Kathmandu, Nepal. BJHS 2017;2 (2)3:175-178.

\section{ABSTRACT}

\section{Introduction}

Laparoscopic cholecystectomy has higher incidence of postoperative nausea and vomiting (PONV). In routine practice single dose of drug is given prophylactically during the surgery.

\section{Objective}

This study aimed to compare the antiemetic efficacy of two different 5-hydroxytryptamine-3 (5HT3) receptor antagonists, Ondansetron and Granisetron when given prophylactically to patients undergoing laparoscopic cholecystectomy.

\section{Methodology}

It was a randomized, single blind study, conducted in 75 patients undergoing laparoscopic cholecystectomy. Patients were divided into two groups: Group $\mathrm{O}$ and Group G. Patients in group $O$ were given $0.1 \mathrm{mg} / \mathrm{kg}$ Ondansetron intravenously (IV) and patients in Group G were given $0.04 \mathrm{mg} / \mathrm{kg}$ Granisetron. The standard general anesthetic technique was administered to all the patients. Episodes of nausea, retching and vomiting were assessed during the first 24 hours after anesthesia. Collected data was applied with appropriate test in SPSS 16 and overall significance level was considered at $95 \%$ confidence interval $(p \leq 0.05)$.

\section{Results}

There was no statistically significant difference for demographic data among the two groups $(P>0.05)$. Both drugs were similarly effective in first four hours $(P>0.05)$. Between 4-12 hours and 12-24 hours, episodes of nausea and vomiting were higher in Ondansetron group.

\section{Conclusion}

The incidence of PONV was significantly high in Ondansetron than in Granisetron given prophylactically in laparoscopic cholecystectomy.

\section{KEY WORDS}

Granisetron, laparoscopic cholecystectomy, ondansetron, PONV 


\section{INTRODUCTION}

PONV is defined as any vomiting, retching or nausea occurring within the first $24-48 \mathrm{~h}$ after surgery. PONV remains one of the most common complications related to surgery and anesthesia. PONV has been characterized as big 'little problem.In all adult patients undergoing surgery incidence of PONV is around $20-30 \%$ of all adult patients. After laparoscopic surgeries the incidence of PONV ranges from $36-82 \%$ and in certain gynecological laparoscopic procedure can be as high as $73 \% .{ }^{4}$

There are multiple contributing factors related for PONV. The factors related to anesthesia are opioids given perioperatively any time or benzodiazepines, inhalational agents, postoperative pain, patient immobilization, wide variation in haemodynamic perioperatively and delayed initiation of oral intake. ${ }^{5}$ If any anti-emetic treatment is not given following laparoscopic Cholecystectomy the incidence of PONV is considerably high. ${ }^{6} \mathrm{PONV}$ is one of the commonest complain following anesthesia, and can result in morbidity like bleeding, pulmonary aspiration of gastric contents, delayed hospital discharge, unexpected hospital admission, fluid and electrolyte disturbances, wound dehiscence, and decreased patient satisfaction. ${ }^{7}$ All these factors reduce the quality of life and interfere with regular patients' treatment. So an effective anti emetic therapy is always required.

Serotonin (5-HT3) receptor antagonist acts on chemoreceptor trigger zone and at vagal afferents in the gastrointestinal tract by producing pure antagonism of the 5-HT3 receptor. Many drugs have been tried to prevent PONV. In 1990s when $5 \mathrm{HT} 3$ receptor antagonist were introduced than a major advance in the treatment of PONV was made because there were very few side effects that were seen with commonly used traditional ant emetics. ${ }^{8}$ The commonly used effective drug for prevention of PONV is Ondansetron; $4 \mathrm{mg}$ intravenously. But another $5 \mathrm{HT} 3$ receptor antagonist Granisetron which is recently introduced has more potent and longer acting activity against. ${ }^{9}$

\section{METHODOLOGY}

This study was comparative, prospective, randomized and single blinded study. After approval from the IRB, NAMS, from the every patients who were enrolled in the study Informed written consent was taken and were randomly allocated into two groups by lottery method. Patients with ASA grade I and II undergoing laparoscopic cholecystectomy of age 15 to 65 years were included. Patients with history of motion sickness, migraine, or any other neurological problems, history of postoperative nausea and vomiting during a previous surgery, who received anyt emetics 48 hours prior to surgery, pregnant/ lactating females and surgery more than two hours were excluded from the study.

\section{Group $\mathrm{G}$ was given $0.04 \mathrm{mg} / \mathrm{kg}$ of Granisetron. Group $O$ was given $0.1 \mathrm{mg} / \mathrm{kg}$ of Ondansetron.}

There were 40 patients in each group. Pre-anaesthetic check up was done one day prior to the surgery, and informed consent was taken. Patient was kept nil per oral at least for 6 $\mathrm{hr}$ prior to anesthesia. Monitors were attached and all baseline hemodynamic parameters were recorded: NIBP,
Pulse, ECG, and $\mathrm{SPO}_{2}$. Intravenous access was done. Patients were preloaded with $10 \mathrm{ml} / \mathrm{kg}$ of ringer lactate over $10 \mathrm{~min}$. Injection Midazolam $0.04 \mathrm{mg} / \mathrm{kg}$ IV and Fentanyl $1.5 \mathrm{mcg} / \mathrm{kg}$ IV was given before induction. Pre-oxygenation was done for 3 minutes. Patients were induced with inj. Propofol $2 \mathrm{mg} / \mathrm{kg}$. After check ventilation patient was paralyzed with muscle relaxant Vecuronium $0.1 \mathrm{mg} / \mathrm{kg}$. Mechanical ventilation was done with bag and mask for 3 minutes ilntubation was done with appropriate size endotracheal tube. Maintained general anesthesia with oxygen, halothane, IPPV and Vecuronium. The study drug was given, 30 minutes before the end of surgery. Reversal of residual muscle relaxation was done with Neostigmine $(0.05 \mathrm{mg} / \mathrm{kg})$ and Glycopyrollate $(0.01 \mathrm{mg} / \mathrm{kg})$. Once extubation criterion was met, the patient was extubated.

The patient was then taken to postoperative care unit. Nausea, vomiting, pulse, blood pressure, both systolic and diastolic was recorded. Any stomach contents expelled from the mouth was referred as vomiting. Involuntary attempt to vomit but no expulsion of stomach contents was referred as retching. ${ }^{15}$ Emesis-free was defined as no any emetic episodes during the specified time period. Nausea and vomiting will be evaluated on a three point scale.

$0=$ none

$1=$ nausea

2 = vomiting. (Retching event was considered as vomiting event)

Nausea assessment was made perioperatively, postoperatively (immediately after tracheal extubation), 0 to $4 \mathrm{hr}, 4$ to $12 \mathrm{hrs}$ and12 to $24 \mathrm{hr}$ thereafter. The percentage of patients who have no vomiting and no nausea during the $24 \mathrm{hr}$ postoperative period in terms of three point scale gave the efficacy of study drugs. Rescue anti emetic for vomiting or persistent nausea at the discretion of a physician or at the patient's request inj. metoclopramide $10 \mathrm{mg}$ IV was given. As a postoperative analgesic supplement, each group received inj. Pethidine $0.8 \mathrm{mg} / \mathrm{kg}+$ Phenargan $0.5 \mathrm{mg} / \mathrm{kg}$ IM 8 hourly. Any complication was managed according to the standard protocols of the hospitals.

Total 80 patients were randomly taken randomly 40 in each group. Three in group $\mathrm{O}$ and two in group $\mathrm{G}$ were excluded. Data collection was done by filling the pro forma prepared by previous study acontaining the demographic details of the patient (age, weight and sex), hemodynamic changes and the severity of PONV at $4 \mathrm{hrs}, 4$ to $12 \mathrm{hrs}$ and 12 to $24 \mathrm{hrs}$.

Data were collected and recorded as per pro forma. Numeric outcome scores were generated from the dummy tables. Collected data was analyzed by means of statistical software SPSS 16 and appropriate tests-chi-square test for proportions like incidence, and severity of PONV and independent t-test for continuous parametric data like age and weight. Overall significance level was considered at $95 \%$ confidence interval $(p<0.05)$. 


\section{RESULT}

Table 1: Comparison of age and weight between two groups $(n=75)$

\begin{tabular}{|l|l|l|l|}
\hline & Group 0 & Group G & P Value \\
\hline Age & $33.42 \pm 6.87$ & $35 \pm 6.49$ & 0.927 \\
\hline Weight & $59.8 \pm 8.4$ & $57.7 \pm 6.34$ & 0.571 \\
\hline
\end{tabular}

Table 2: Incidence of PONV in two groups $(n=75)$

\begin{tabular}{|c|c|c|c|}
\hline \multirow{2}{*}{ Group } & \multicolumn{2}{|c|}{ PONV } & \multirow{2}{*}{ P Value } \\
\cline { 2 - 3 } & Absent & Present & \\
\hline Group G & $28(73.7 \%)$ & $10(26.3 \%)$ & \\
\hline Group O & $17(45.9 \%)$ & $20(54.1 \%)$ & \\
\hline
\end{tabular}

Table 3 Incidence of PONV in two groups in different time intervals $(n=75)$

\begin{tabular}{|l|c|c|c|}
\hline $\begin{array}{l}\text { Nausea vomiting } \\
\text { different time period }\end{array}$ & $\begin{array}{c}\text { Group } \\
(\mathbf{n = 3 7})\end{array}$ & $\begin{array}{c}\text { Group G } \\
(\mathbf{n = 3 8 )}\end{array}$ & P value \\
\hline $\mathbf{0}$ to $\mathbf{4}$ hours & & & \\
\hline No Nausea Vomiting & $29(78.3 \%)$ & $31(81.5 \%)$ & 0.808 \\
\hline Nausea & $6(16.6 \%)$ & $6(15.7 \%)$ & 0.427 \\
\hline Retching or vomiting & $2(5.4 \%)$ & $1(2.6 \%)$ & 0.434 \\
\hline $\mathbf{4}$ to 12 hours & & & \\
\hline No Nausea Vomiting & $19(51.3 \%)$ & $36(94.7 \%)$ & 0.001 \\
\hline Nausea & $14(37.8 \%)$ & $2(5.2 \%)$ & 0.002 \\
\hline Retching or vomiting & $4(10.8 \%)$ & $0(0 \%)$ & 0.001 \\
\hline 12 to 24 hours & & & \\
\hline No Nausea Vomiting & $25(67.5 \%)$ & $34(89.4 \%)$ & 0.026 \\
\hline Nausea & $7(18.9 \%)$ & $3(7.9 \%)$ & 0.042 \\
\hline Retching or vomiting & $5(13.5 \%)$ & $1(2.6 \%)$ & 0.021 \\
\hline
\end{tabular}

Total 75 patients were included and were comparable between the two groups with respect to age and weight. Male patients included in $\mathrm{O}$ group were six and in $\mathrm{G}$ group were five. Twenty eight(75.6\%) of ASA I and 9 (24.3\%) ASA II were included in group $\mathrm{O}$ and $28(73.6 \%)$ of ASA I and $10(26.3 \%)$ of ASA II were included in group G. Two groups were comparable and statistically not-significan. (Pvalue $>0.05$ ).

There were total 6 males and 31 females in group 0 and 5 males and 33 females in group $\mathrm{G}$. The distribution of sample among both the group was found to be statistically nonsignificant. Among 39 total females, 14 experienced nausea and 11 experienced vomiting. Among 11 male patients, no patient experienced nausea and vomiting.

Duration of surgery divided into two groups as less than 1 hour and one to two hours. In group 0, 19 patients were within one hour group and 23 patients were within one hour group in G group. Similarly 18 patients were in one to 2 hour group in group $\mathrm{O}$ and 15 in group $\mathrm{G}$. This data is statistically non significant between two groups as $p$ value is 0.424 ( $P$ value $>0.05$ ). Incidence nausea in patients for surgical time $<1$ hour is $11.9 \%$, in comparison to $24.2 \%$ in patients with surgical time 1 to 2 hours. Similarly, vomiting is also $2.3 \%$ in patient with surgical time $<1$ hours and $33.3 \%$ in patients with surgical time 1 to 2 hours.

\section{DISCUSSION}

PONV is very unpleasant side effects of surgery and anesthesia, which causes dissatisfaction and distress to patients. PONV is of multi-factorial origin. The incidence of PONV after general anesthesia, despite the advances in antiemetic therapy is still found to be high. Gold et al noted that the most common reasons requiring admission after day care surgery are bleeding, pain, and PONV. ${ }^{10}$ litomi T et al shows 3.2 times greater risk of PONV in laparoscopy cholecystectomy than laparotomy cholecystectomy. ${ }^{11}$

Aspinall and Goodman have suggested a placebo-controlled trial is unethical when there is anti emetic drug available because after laparoscopic surgeries PONV is distressing. ${ }^{12}$ It was decided not to include a control group in this study. Total 80 cases were randomized, 40 patients in each group. Total excluded cases were five. Three cases were excluded due to Laparoscopic cholecystectomy converted to open cholecystectomy and two were excluded due to increase in duration of surgery more than two hours.

Incidence of PONV in Ondansetron group is 54\% in this study. Similar incidence was found in study done by Mohamad Ommid et al is $52 \% .{ }^{13}$ In study done by Bhattacharya et al found the incidence of PONV in Odansetron group was $10 \%$ this difference in incidence in PONV might be due to variation of type of surgery and short duration of surgery in relation to this study. ${ }^{14}$ Study done by Gupta et al incidence of PONV is $70 \%$ which is higher in incidence to this study this might be due to drug given at the time of induction instead of at the end of surgery that was done in this study. ${ }^{15}$

Incidence of PONV in Granisetron group is $26 \%$ in this study. In the study done by Ommid et al there was $29 \%$ incidence of PONV. $^{13}$ The result was similar to this study. Study done by Bhattacharya et al found the incidence of PONV in Granisetron group was $7 \%$ this difference in incidence in PONV might be due to variation in type of surgery and short duration of surgery in relation to this study. ${ }^{14}$ In study done by Gupta et al incidence of PONV was 45\% in Granisetron group which is higher in incidence to this study. ${ }^{16}$ This might be due to drug given at the time of induction instead of at the end of surgery that was done in this study. In this study, 26\% patients in Granisetron group as compared to $54 \%$ in Ondansetron group have PONV; the difference incidence was statistically highly significant. In the study done by Ommiad et al the result were similar to this study. ${ }^{13}$ Granisetron group has $20 \%$ incidence of PONV as compared to $52 \%$ in Ondansetron group and the study was also conducted in laparoscopic cholecystectomy. But Bhattacharya et al in 2003 in Kolkata found incidence of PONV $10 \%$ patients in 
Granisetron group as compared to $20 \%$ in Ondansetron group. The incidence of PONV in our study is less compared to incidence of PONV in that study. This difference may be explained by variation in type and the duration of surgical procedure in the study done. They studied patients undergoing laparoscopic tubal ligation under general anaesthesia and post operative opioid analgesia was avoided and only diclofenac was introduced. Mean duration of surgery was $36 \pm 10$ minutes in their study and mean duration of study was $65 \pm 15$ minutes in this study. In this study, incidence of nausea in first 4 hours was significant in both the groups. In Ondansetron group incidence of nausea was $6(15.7 \%)$ and in Granisetron group was 6 (16.2\%) experienced nausea but difference in incidence of nausea between two groups was not-significant (P-value $<0.05)$. Incidence of vomiting episodes in Ondansetron group were $2(5.4 \%)$ as compared to $1(2.6 \%)$ in Granisetron group which was also statistically not significant (P-value $>0.05)$. Ommid et al found similar result in first $6 \mathrm{hrs}$ of postoperative period $7(14$ $\%$ ) in Granisetron group experienced nausea and 2(4\%) experienced vomiting and in Ondansetron group $11(22 \%)$ experienced nausea and 5(10\%) experienced vomiting. In our study incidence of nausea is greater than the incidence of nausea from 4 to 12 hours after surgery was 38\% in Ondansetron group and $13 \%$ in Granisetron group which was statistically significant ( $p$ value $<0.05$ ) in this study. Study done by Gupta at el found the incidence of PONV in Ondansetron group was $60 \%$ patients, Granisetron group was $25 \%$ patients and Metoclopramide group was $90 \% .{ }^{15}$ The study done by Ommid et al also found that incidence of PONV in Ondansetron group was $46 \%$ and incidence of PONV in Granisetron group was $12 \% .{ }^{13}$ This was statistically significant ( $p$ value $<0.001$ ) which is similar to this study. In this study there is statistically significant reduction of nausea

\section{REFERENCE}

1. Watcha MF, White PF. Post operative nausea and vomiting. Anesthesiology 1992; 77(1): 162-84.

2. Kapur PA.The big "little problem". Anaesthesia Analgesia1991; 73:243-45.

3. Fuji $\mathrm{Y}$, Tanaka $\mathrm{H}$, Toyooka $\mathrm{H}$. The effect of Dexamethasone on antiemetics in female patients underling gynaecological surgery. Anesthesia Analgesia 1997; 85: 913-917.

4. Diemunsch P, Schoeffler P, Bryssine B. Antiemetic activity of the NK1 Receptor antagonist in the treatment of established post operative nausea and vomiting after major gynecological surgery. British Journal of Anaesthesia 1999; 82:274-276.

5. Yogendran S, Sunthera LY. A prospective randomized double blinded study of the effect of intravenous fluid therapy on adverse outcomes in outpatient surfer. Anesthesia Analgesia 1995; 80:682-686.

6. Apfel CC, Greim CA, Haubitz I, Grundt D, Goepfert C, Sefrin P, Roewer N. The discriminating power of a risk score for postoperative vomiting in adults undergoing various types of surgery. Acta anaesthesiologica scandinavica. 1998 May 1;42(5):502-9.

7. Ku CM, Ong BC. Postoperative nausea and vomiting: a review of current literature. Singapore medical journal. 2003 Jul;44(7):366-74.

8. Paxton DL, Mekay CA, Mirakin KR, prevention of nausea and vomiting after day case gynaecologicall laparoscopy. Anaesthesia 1995; 50:403-406.

9. Andrews PRR, Bhandari P, Davey PT, Binghar $S$ et al. Are all $5 \mathrm{HT} 3$ receptor antagonist the same? Eur J Cancer 1992; 28A: 52-56.

10. Gold BS, Kitz DS, Lecky JH, Neuhaus JM. Unanticipated admission to the hospital following ambulatory surgery. Jama. 1989;262(21):3008-10. in two groups in 12 to 24 hours. Incidence of nausea was $19 \%$ in Ondansetron group and $8 \%$ in Granisetron group which was statistically significant ( $p$ value $<0.05$ ). Incidence of vomiting was $13 \%$ in Ondansetron group and $3 \%$ in Granisetron group. But the overall incidence of nausea and vomiting was decreased in 12 to 24 hours than in first 12 hours. Ommid et al found statistically significant difference in nausea in 12 to 24 hours but incidence of vomiting was not significant between the two groups. ${ }^{13}$ Similarly Gupta at el also found statistically not significant data in 12 to 24 hours in incidence of vomiting. ${ }^{15}$

\section{CONCLUSION}

This study concluded that Granisetron is more effective given prophylactically than Ondansetron given prophylactically for prevention of PONV following laparoscopic cholecystectomy in the first 24 hours.

\section{RECOMMENDATIONS}

We recommend the prophylactic antiemetic Inj. Granisetron $0.04 \mathrm{mg} / \mathrm{kg}$ intravenous at the end of laparoscopic cholecystectomy to prevent Post operative nausea and vomiting.

\section{LIMITATION OF THE STUDY}

Only laparoscopic cholecystectomy patients were involved.

\section{ACKNOWLEDGEMENT}

We would like to acknowledge all respondents, post operative ward staff, seniors and my family for their support, time and participation, without them this study wouldn't have been possible.

\section{CONFLICT OF INTEREST}

Authors declare no conflict of interest.

11. litomi T, Toriumi S, Kondo A, Akazawa T, Nakahara T. Incidence of nausea and vomiting after cholecystectomy performed via laparotomy or laparoscopy. Masui The Japanese journal of anesthesiology. 1995;44(12):1627-31

12. Aspinall RL, Goodman NW. Denial of effective treatment and poor quality of clinical information in placebo controlled trials of ondansetron for postoperative nausea and vomiting: a review of published trials. BMJ. 1995;311(7009):844-6.

13. Ommid M, Ahmad M, Jehan N, Shiekh FI, Nazir S, Nissa G. Comparative evaluation of ondansetron and granisetron in prevention of postoperative nausea and vomiting following laparoscopic cholecystectomy in females. IOSR Journal of Dental and Medical Sciences Jan-Feb. 2013;4(1):15-20.

14. Bhattacharya D, Banerjee A. Comparison of ondansetron and granisetron for prevention of nausea and vomiting following day care gynaecological laparoscopy. Indian J Anaesth. 2003;47(4):249-82.

15. Gupta V, Wakhloo R, Lahori V, Mahajan MK, Gupta SD. Prophylactic antiemetic therapy with ondansetron, granisetron and metoclopramide in patients undergoing laparoscopic cholecystectomy under general anaesthesia. Internet Journal of Anesthesiology. 2007;14(1):1-5.

16. Gupta $P$, Jain S. Postoperative nausea and vomiting prophylaxis: A comparative study of ondansetron, granisetron and granisetron and dexamethasone combination after modified radical mastectomy. Saudi journal of anaesthesia. 2014;8(Suppl1):S67. 